\title{
AVALIAÇÃO DA FUNÇÃO PULMONAR POR OSCILOMETRIA DE IMPULSO EM CRIANÇAS SIBILANTES E CONTROLES
}

Pôster

Autores deste trabalho:

Patrícia Polles de Oliveira Jorge: Universidade Federal de São Carlos - UFSCar Jales Henrique Pereira de Lima: Universidade Federal de São Paulo - Escola Paulista de Medicina - UNIFESP-EPM

Dirceu Solé: Universidade Federal de São Paulo - Escola Paulista de Medicina UNIFESP-EPM

Gustavo Falbo Wandalsen: Universidade Federal de São Paulo - Escola Paulista de Medicina - UNIFESP-EPM

Área do Trabalho: Pediatria

Data da submissão:10/08/2018 às 10:05

\section{Justificativa}

O diagnóstico de asma baseia-se no quadro clínico, exame físico e na avaliação da função pulmonar. Em crianças menores de 6 anos, a espirometria é difícil de ser realizada. O sistema de oscilometria de impulso (IOS) avalia a função pulmonar sem a necessidade de sedação e não depende de esforço.

\section{Objetivo(s)}

Avaliar a função pulmonar por meio de IOS em pré-escolares com asma.

\section{Método(s)}

Participaram pacientes asmáticos e controles de 3 a 6 anos. O estudo foi aprovado pelo CEP (CAAE: 55277516.3.0000.5505). Utilizamos questionário EISL (Estudio Internacional de sibilancia em lactantes) para investigar presença de sibilos, entre outros, o GINA para classificar gravidade e o TRACK para avaliar frequência de crises. IOS foi realizada com o MasterScreenTM (CareFusion, EUA). Foram obtidas 3 medidas antes e após salbutamol e registrado valores de resistência a $5 \mathrm{~Hz}$ (R5) e $20 \mathrm{~Hz}$ (R20), reactância a $5 \mathrm{~Hz}(X 5)$, frequência de ressonância (Fres), área de reactância ( $A X)$ e resposta broncodilatadora (BD) (diminuição de $25 \%$ no $\mathrm{R} 5$ ).

\section{Resultado(s)}

Foram avaliadas 224 crianças (150 asmáticos e 74 controles), 53\% do sexo masculino, mediana de 5,1 anos. Entre os asmáticos, 70\% tiveram sibilos no primeiro ano, 87,3\% sibilos no último ano, $34 \%$ sibilos no último mês, $41 \%$ eram grau leve, $15 \%$ moderado e $44 \%$ grave. A mediana de $\mathrm{R} 5$ dos asmáticos foi 1,01 e a dos controles foi 0,9 . Houve diferença significativa nos valores de R5, R5-R20 e resposta BD entre asmáticos e controles $(p=0,02, p=0,07$ e $p<0,01)$. Sibilos no último mês associou-se a aumento de R5 e Fres $(p=0,01$ e $p=0,04)$ e fumo na gravidez a aumento de $A X(p=0,02)$. Houve tendência de aumento de R5 e AX entre os meninos ( $p=0,07$ e $p=0,08)$, e de resposta $B D$ entre os com dificuldade para respirar no último ano $(p=0,06)$. 


\section{Conclusão(ões)}

R5 e Fres foram associados à sibilo no último mês, $A X$ foi associado a fumo na gravidez. Houve diferença nos valores de R5, R5-R20 e resposta BD dos asmáticos comparados aos controles. 